\section{Teaching Junior High School Physics: Personal Experiences and Observations}

In my thirty years as a university science and engineering professor, I have always wondered about the apparent lack, among American-educated students, of a basic understanding of fundamental physical principles. Why doesn't the average student know the functions of simple everyday devices such as a light bulb, an electro motor, a transformer, a battery, or a resistor? Moreover, why do these students apparently lack the joy and excitement of discovering the laws and secrets of nature?

Part of the key to answering these questions undoubtedly must be sought at the lower educational levels. That is why I welcomed the opportunity to teach a "physics block" in a Waldorf school. In Waldorf schools, children are intensively exposed to a certain study area, such as chemistry, biology, history, or literature, for the first two hours of each school day, for three to four weeks. Waldorf schools also try, whenever possible, to combine various study areas. For example, teachers strive to intersperse physics with elements of philosophy, art, or history. My assignment was to introduce the 7 th and 8 th graders to the foundations of mechanics.

Our first endeavor was to explore the laws of pulleys and tackles. To do this, we hung a pulley from the ceiling, threaded a rope around the roller, and attached bricks of equal size and weight to each end. Quite naturally, and to nobody's surprise, the bricks held each other in balance unless someone pushed or pulled on one of them. Next, we fastened one end of a rope to the ceiling and threaded the other end through a movable pulley on which we hung a brick. The free end of the rope was then strung around a fixed pulley which was attached to the ceiling. This end of the rope was connected to only half a brick. Then came the question to the class: Why is it that half a brick can counterbalance a full brick? The question was not immediately answered by the pupils. Several incorrect suggestions were proposed, including magic or tricks. We took our time. After half an hour of experimentation, guessing, and steadily increasing excitement, I asked one student to hold one of the bricks in each hand and to move the hands up and down. Suddenly she exclaimed, "I have to move one hand a much greater distance than the other hand!!" Now everyone wanted to try it. This took another 15 minutes or so. Finally, everyone seemed to have shared the revelation that a movable pulley halves the necessary force while it doubles the travel distance. Philosophical remarks entailing how a weak person can double (or quadruple) his strength were discussed in order to bring this physical phenomenon into a larger, that is, human, context. At home, the pupils drew colorful pictures about the day's events in their own notebooks.

On another day, when studying the laws of an inclined plane, we wondered how the ancient Egyptians might have brought their heavy stones to the top of a pyramid. We discussed that the Egyptians might have piled up a ramp, consisting of mud from the Nile River, beside a pyramid on which they pulled their load. This ramp decreased the necessary force compared to a straight vertical lift. We studied the appertaining laws by experimenting with some simple devices, including a cart, an inclined plane, and some weights. The students eventually discovered for themselves that the smaller the slope, the less force is necessary for the lifting process.

On still another day, we investigated the laws of levers. First we constructed a seesaw from a $4 \times 4$ wooden beam and a wooden block. Then two approximately equal-sized children sat on the ends of the seesaw. After playing with this device for some time, I selected the heaviest boy and a small girl to sit on the opposing ends and we moved the fulcrum closer to the boy. You should have seen the excitement when the balance was eventually reached! Then

The Education Exchange highlights the experiences of scientists and engineers with local schools, along with helpful hints and resources. If you would like to share your own involvement in science education, contact Finley Shapiro, Department of Electrical and Computer Engineering, Drexel University, Philadelphia, PA 19104, U.S.A.

Telephone (215) 895-6749

Fax (215) 895-1695

Email: shapiro@ece.drexel.edu

To receive additional information on how you can get involved in enhancing K-12 science education, circle number 120 on the Reader Service Card. we moved the fulcrum very close to one end of the beam. Over the shorter end we placed the crossbar between two legs of a table. At first, one child sat on the table and could easily be lifted by someone else pressing on the longer side of the lever. Then another child sat on the table, then another child, and so forth, until the pupils requested that even I had to sit on the table. Still, all of us could be lifted by only one child. We discussed how one person can move a large crowd. Then we talked about other types of levers. The children were allowed to go around the room and onto the school grounds to search for devices that function on the lever principle. It was interesting to observe how many levers they found, such as a nutcracker, a light switch, a clothes pin, etc.

The greatest excitement occurred on the day when we dropped bricks from various heights off a fire escape and measured their descent time. It came to most everyone's surprise that the bricks increased their velocity the longer distance they fell. We found the laws of free fall. We discussed how, hundreds of years ago, Leonardo da Vinci made similar experiments (supposedly involving the inclined tower of Pisa). Then we learned about other inventions and works of art created by Leonardo.

These experiments (and many others) that we performed were quite simple, inexpensive, and "transparent." In my view, there is no need to derive complicated equations in junior high school physics and to make the pupils solve mathematical-physical problems. This can largely wait until high school and college. Such problem-solving often bores the students and eventually drives them away from science or engineering. The main task in junior high schools is instead to bring an awareness of the laws of physics to the younger generation and to excite them.

Today, the children and I look back with a great deal of pleasure and pride when we browse through the class books prepared by each student as part of their homework assignment. No science textbooks were presented to the pupils. Their learning came through observations, experimentation, and by creating their own journals. It is hoped that this experience will plant a seed in these young souls which eventually might cause some of them to want to understand more of the mysteries of science.

ROLF E. HUMMEL

Rolf E. Hummel, a member of the Materials Research Society, is a professor in the Department of Materials Science and Engineering, University of Florida, Gainesville, Florida 32611-2066. 


\section{Key Sources for Timely Issues in Materials Research}

\section{INTERNATIONAL JOURNAL OF POLYMERIC MATERIALS}

\section{Editor in Chief \\ D.C. Prevorsek}

This journal provides a forum for reliable polymer property information which can help the designer, fabricator and consumer in optimizing the choice and use of polymers, particularly as engineering materials. Emphasis is placed on the understanding of mechanisms and the interaction of engineering properties with chemical structure and morphology. Papers related to the processing of composites and elastomers are also included. The journal is interdisciplinary in nature and contributions are welcomed from chemists, physicists, engineers and designers.

\section{Subscription Information}

4 issues per volume - ISSN: 0091-4037

\section{POLYMER NEWS}

\section{Editor in Chief}

\section{G.S. Kirshenbaum}

Polymer News provides comprehensive coverage of the rapid research taking place in both the industrial and academic worlds. This monthly magazine discusses such topics as elastomers, packaging polymerization processes, composites and thermosets. With its diversity of scope and expanded format, the journal holds a strong appeal for chemists as well as product developers, business experts and marketing managers.

Contents: Comment - Feature Articles Columns - Market Studies - New Products and Processes - Centers of Polymer Research Conference Reports - Book Reviews Meetings-Calendar of Events

\section{Subscription Information}

12 issues per volume - ISSN: 0032-3918

“...The most thorough treatment of the subject imaginable..."

-stig Friberg, Clarkson University, Potsdam, New York

\section{Editor in Chief \\ Louis H. Sharpe}

Celebrating its 25th year in publication, this journal serves the large technical community concerned with the development of an understanding of the phenomenon of adhesion and its practical applications. The Journal of Adhesion provides a forum for discussion of basic and applied problems in adhesion. Papers are considered relevant if they contribute to the understanding of the response of systems of joined materials to mechanical or other disruptive influences.

\section{Subscription Information}

4 issues per volume - ISSN: 0021-8464

For a FREE journal sample copy or price information call or FAX:

\section{GORDON AND BREACH}

\section{SCIENCE PUBLISHERS}

P.O. Box 786 Cooper Station, New York, NY 10276, USA Tel. (800) 545-8398 - (212) 243-4411 + FAX (212) 645-2459

OR P.O. Box 90, Reading, Berkshire RG1 8JL, UK

Tel. (0734) 568316 - FAX (0734) 568211

\section{POLYMERIZATION IN ORGANIZED MEDIA}

\section{Edited by C.M. Paleos}

This book summarizes the current state of knowledge concerning the effect of orientational and spatial ordering of monomers on the polymerization process. Some of the techniques covered in this volume that bring about such ordering involve thermotropic and lyotropic liquid crystalline media, gas-water and gas-solid interfaces, micelles and microemulsions. Potential applications range from novel composite media to biopolymer synthesis. 1992 - ISBN: 2-88124-538-2 - Hardcover - 375 pp. List price: $\$ 110.00$ - Price for individuals: $\$ 70.00^{*}$

* Please contact the publisher for details.

US dollar price applies to North America only. All other countries should contact the publisher for applicable price. Prices subject to change without notice. 


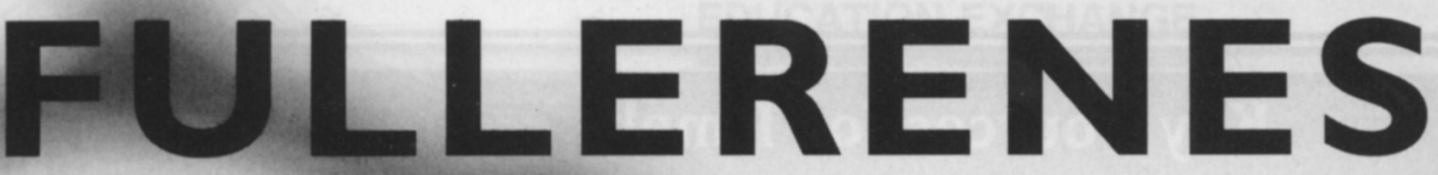

\section{The First International Interdisciplinary Colloquium on the Science and Technology of the Fullerenes}

\section{Santa Barbara, California, USA 27th June - 1st July 1993}

Program chair: Harold Kroto, University of Sussex, UK

Coordinator: David Walton, University of Sussex, UK

FULLERENES ' 93 will consist of:

- Eight discussion sessions over four days

- Invited reviews by key fullerene researchers

- Poster presentations on topical aspects of fullerene research

\section{REGISTRATION}

Save $\$ 100.00$ by registering for Fullerenes ' 93 at the Pergamon Booth at the MRS Spring Meeting.

Registrations taken at the MRS Spring Meeting (12 - 16 April 1993)

Registrations before 31 st March 1993

US $\$ 395.00$

Student Registrations before 3 I st March 1993

*Subject to confirmation of student status

All other registrations after 3 Ist March 1993

US $\$ 395.00$

US $\$ 195.00$

US\$495.00

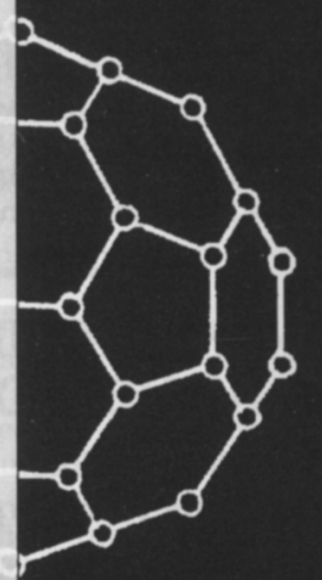

Get your copy of:

\section{THE FULLERENES}

EDITED BY:

H. W. Kroto, University of Sussex, UK

J. E. Fischer, University of Pennsylvania, USA

D. E. Cox, Brookhaven National Laboratory, USA

$189 \times 272 \mathrm{~mm}$ 340pp 307 Illus

15 Photos Over 1200 Lit Refs March 1993

$10 \%$ Discount available on orders taken at the Pergamon Booth

ISBN 0080421520 List Price US\$53.95

Registration information for the colloquium and order forms for the book are available at the Pergamon Booth or by contacting:

Kim Cavellero, Pergamon Seminars, 660 White Plains Rd, Tarrytown, NY 10591-5153, USA 


\section{$\square$ STRUCTURES OF PERMANENT}

\section{MAGNETS:}

Generation of Uniform Fields

Manlio G. Abele

Provides the design theory, logic, and quantitative design criteria apolicable to the development of efficient magnetic structures. Reviews the fundamental concepts of magnetostatics and the analysis of problems, followed by a formulation of the design of closed magnetic structures, and an analysis of the opening of the magnetic structures and demagnetization characteristics of real magnetic material.

0471-59112-2 April 1993 400pp \$69.95

\section{$\square$ PAYSICAL PROPERTIES OF III-V} SEMICONDUCTOR COMPOUNDS:

InP, InAs, GaRs, GaP, InGaAs, and

InGaAsP.

\section{Sadao Adachi}

Presenting a theoretical and practical treatment of various material properties of InGaAsP and InGaAs alloy semiconductors, this book also emphasizes the properties of related binary semiconductors. The result is a summary in graphical, tabular, and functional forms, of most of the important theoretical and experimental data.

0471-57329-9 Sept. $1992 \quad 336 p p \quad \$ 64.95$

\section{WAVE MECHANICS \\ APPLIED TO SEMICONDUCTOR HETEROSTRUCTURES \\ Gerald Bastard}

This book is specifically concerned with the basic electronic and optical properties of two dimensional semiconductor heterostructures based on III-V and II-V compounds. It explores various consequences of onedimensional size-quantization on the most basic physical properties of heterolayers.

0471-21708-1 Jan. 1991 339pp \$48.95 pr.

\section{$\square$ PHOTOCHEMICAL VAPOR DEPOSTIOH}

\section{J.G. Eden}

Provides an overview of photochemical vapor deposition, its characteristics and potential. Eden einphasizes the properties of films that have been developed using this versatile new technqiue and describes the conditions under which they were grown. 0471-55083-3 Sept. 1992 210pp \$54.95
New and

Best-Selling

Materials Research

Books-

\section{Yours to Examine}

\section{Free for 15 days!}

\section{MOECULA DYNAMIC \\ SIMULATION \\ Elementary Methods}

James M. Haile

Aimed at the novice, this book demonstrates how molecular dynamic simulations work and how to perform them. Stressing easy-to-use methods, the book includes sample calculations, figures, problems and four complete FORTRAN codes.

0471-81966-2 June $1992 \quad 489 p p \quad \$ 59.95$

\section{$\square$ A SCIENTISTS AND ENGINEER'S GUIDE TO WORKSTATIONS AND SUPERCOMPUTERS:}

Coping with Unix ${ }^{\mathrm{TM}}$, RISC, Vectors and Programming

Rubin Landau \& Paul J. Fink, Jr.

This book/disk package is for the working scientist and engineer who need to do technical computing on UNIX workstations or vector/parallel supercomputers. New users learn how to set up hardware, software and communications; more experienced users learn techniques and tools for creative and effective computation.

0471-53271-1 Nov. 1992 450pp \$49.95 pr.

\section{CRYSTALLOGRAPHY IN MODERW \\ CHEMISTRY:}

A Resource Book of Crystal Structures Thomas C.W. Mak and Gong-Du Zhou

This unique reference provides professionals and students with a broad survey of the crystal and molecular structures of all major classes of compounds along with examples and up-to-date references. Each section features a principal crystal structure and includes numerous figures.

0471-54702-6 June $1992 \quad 1,344 p p \quad \$ 175.00$

\section{COMPUTING FOR SCIENTSTS AND} ENGINEERS:

A Workbook of Analysis, Numerics and Applications

\section{William J. Thompson}

An essential workbook, providing the complete background for algorithms used in data analysis, imaging and signal processing, as well as the reasoning behind numerical recipes. Includes 27 interactive sample programs in $\mathrm{C}$ readily adaptable to Fortran and Pascal, 271 examples and exercises. Suitable for selfstudy and formal classes.

0471-54718-2 Oct. $1992 \quad 464 p p \quad \$ 54.95$

\section{$\square$ FUNDAMENTAL PRINGIPLES OF POLYMERIC MATERIALS \\ Second Edition \\ Stephen L. Rosen}

Fully revised and updated, this book covers the fundamental principles of polymer science and engineering that are of practical relevance. Rosen offers a unified introduction to the field as well as a foundation for more advanced study. Includes examples and problems.

0471-57525-9 Jan. $1993 \quad 432 p p \quad \$ 59.95$

\section{INTRODUCTION TO PHYSICAL POLYMER SCIENCE \\ Second Edition \\ L. H. Sperling \\ Revised and updated, this new edition of a bestselling text/reference presents a detailed treatment of the role ofmolecular conformation and configuration in determining the physical behaivor of polymers \\ 0471-53035-2 July $1992 \quad 524 p p \quad \$ 64.95$}

\section{FERMI-LIQUID THEORY:}

Concepts and Applications

G. Baym \& C. Pethick

0471-82418-6 $1992 \quad 216 p p \quad \$ 54.95$

\section{NORGANIC MATERIALS}

Edited by D.W. Bruce and D. O'Hare

0471-92889-5 $1993 \quad 450 p p \quad \$ 99.00$

\section{A PRIMER OF DIFFISION PROBLEMS \\ R. Ghez}

0471-84692-9 $1988 \quad 243 p p \quad \$ 44.95$ pape

Circle No. 50 on Reader Service Card.

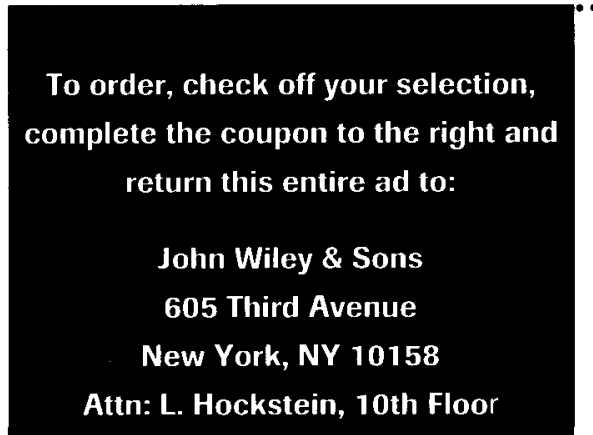

$\square$ Send for 15 days exam with bill $\square$ Payment enclosed (prepaid orders are sent postpaid) Name:

Firm:

Address

City/State/Zip

Signature:

To order by Phone, Call Toll-Free 1-800-225-5945 All other inquiries, call (212) 850-6418 